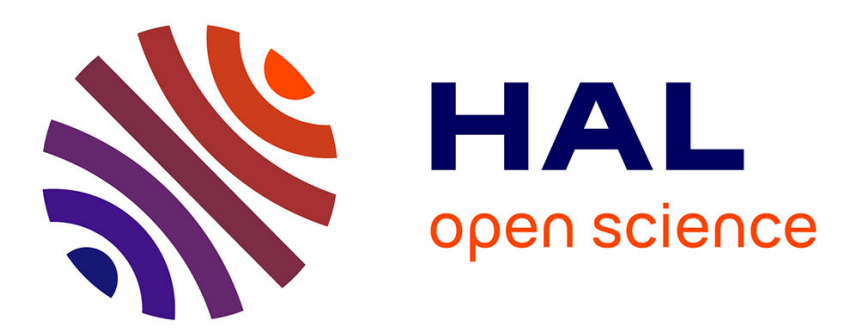

\title{
Oxidation of metallic alloys to produce high Tc superconducting oxide/Ag microcomposites
}

\author{
Wei Gao, John B. Vander Sande
}

\section{To cite this version:}

Wei Gao, John B. Vander Sande. Oxidation of metallic alloys to produce high Tc superconducting oxide/Ag microcomposites. Journal de Physique IV Proceedings, 1993, 03 (C9), pp.C9-187-C9-196. 10.1051/jp4:1993917 . jpa-00252354

\section{HAL Id: jpa-00252354 https://hal.science/jpa-00252354}

Submitted on 1 Jan 1993

HAL is a multi-disciplinary open access archive for the deposit and dissemination of scientific research documents, whether they are published or not. The documents may come from teaching and research institutions in France or abroad, or from public or private research centers.
L'archive ouverte pluridisciplinaire HAL, est destinée au dépôt et à la diffusion de documents scientifiques de niveau recherche, publiés ou non, émanant des établissements d'enseignement et de recherche français ou étrangers, des laboratoires publics ou privés. 


\title{
Oxidation of metallic alloys to produce high $T_{\mathrm{c}}$ superconducting oxide/Ag microcomposites (*)
}

\author{
Wei Gao and John B. Vander Sande
}

Department of Materials Science and Engineering, Massachusetts Institute of Technology, Cambridge, MA 02139, U.S.A.

\begin{abstract}
A metallurgical/high temperature oxidation method has been developed to produce high $T_{c}$ superconductors. Metallic precursor alloys were produced by vacuum melting and rapid solidification. Ag was added to the alloy to improve processing and mechanical properties. These alloys were subjected to controlled oxidation and annealing to convert them into high $T_{\mathrm{c}}$ superconductors. $\mathrm{Bi}-\mathrm{Pb}-\mathrm{Sr}-\mathrm{Ca}-\mathrm{Cu}-\mathrm{O} / \mathrm{Ag}$ superconducting microcomposites with zero resistance at $104-110 \mathrm{~K}$ were produced in this way. The oxidation kinetics and oxide structure were studied by thermogravimetry, electron microscopy and microanalysis. The formation of the superconducting oxides was studied by establishing a set of temperature-time-transformation (TTT) diagrams. Mechanical deformation was also introduced to produce samples with a textured microstructure and improved $J_{\mathrm{c}}\left(\sim 10000 \mathrm{~A} / \mathrm{cm}^{2}\right.$ at $\left.77 \mathrm{~K}\right)$. The metallic oxidation method has advantages in mass production of superconductors in the forms of long ribbons and coils with improved mechanical properties.
\end{abstract}

\section{Introduction.}

Metallic oxidation can be used as a method to produce advanced materials including composites [1, 2] and high $T_{\mathrm{c}}$ oxides [3, 4]. The basic idea is to oxidize metallic precursors under controlled conditions to produce oxide materials with designed composition, microstructure and properties. Stable metals (e.g., Ag) have been added to produce oxide/metal microcomposites in an effort to vary their properties. This paper reports the processing and characterization of $\mathrm{Bi}-\mathrm{Pb}-\mathrm{Sr}-\mathrm{Ca}-\mathrm{Cu}$ high $T_{\mathrm{c}}$ oxide/Ag superconducting microcomposites produced by this method.

\section{Processes for producing metallic precursors.}

Metallic precursors can be made by melt spinning [3, 4], melt dipping [5, 7], melt writing [8], and virtually any process of metal forming, depending upon the required shape. Rapid solidification techniques produce precursor alloys with a homogeneous, fine-grained microstructure. Therefore, this approach can be used for a wide range of alloy compositions, which otherwise might be difficult to produce as homogeneous alloys.

The precursor alloys were made by mixing and melting the pure metals together under an Ar atmosphère. The alloys were then remelted in a crucible and ejected through a nozzle onto a rotating $\mathrm{Cu}$ wheel. This process produces alloy ribbons of $20-100 \mu \mathrm{m}$ thick, $1-10 \mathrm{~mm}$

(*) Invited paper. 
wide, and virtually infinite in length. The thickness and width of the ribbons can be varied by controlling the processing parameters. Flexible alloy ribbons with maximum bending strains of $0.7-1.5 \%$ have been produced by using carefully controlled processing parameters [6], and superconducting coils with diameters as small as $8 \mathrm{~mm}$ can be made by first winding the metallic precursor ribbons on a spool, followed by suitable oxidation and annealing (wind \& react approach).

The melt dipping technique also includes melting the precursor alloy in a crucible under an $\mathrm{Ar}$ atmosphere. A preheated substrate was dipped in the melt and pulled out, resulting in a layer of precursor alloy coating attached to the surfaces. $\mathrm{MgO}, \mathrm{SrTiO}_{3}, \mathrm{Al}_{2} \mathrm{O}_{3}, \mathrm{Ag}$ and stainless steels were used as substrates, and precursor alloy coatings from 5-100 $\mu \mathrm{m}$ thick were produced in this way [7]. The thickness and adhesion of the dipped coatings depended upon the temperature of the melted alloy and the substrate, the liquid-substrate contact time, and the nature of the substrate.

Melt writing is another method to make precursor coatings for producing superconductors. The precursor alloys were again melted in a tube, and ejected through a nozzle onto a substrate. Both the tube and the substrate can move to produce precursor alloys in the forms of long wire, long ribbon, coil and virtually any type of "written" pattern. The substrate can be chosen to ensure good adhesion between the coating and substrate, and the thickness and width of the coatings can be controlled by adjusting the processing parameters [8]. This method can also provide joining for superconductors with superconductors or normal metals.

Superconductor coatings have also been produced by a press-coating technique, a method to press single or multilayered oxidized ribbons on a strong, tough substrate [9]. The pressing process deforms the specimen and produces a textured microstructure with improved $J_{c}$. Figure 1 is a schematic drawing for the processes described above.

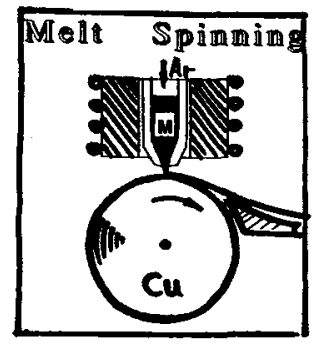

a

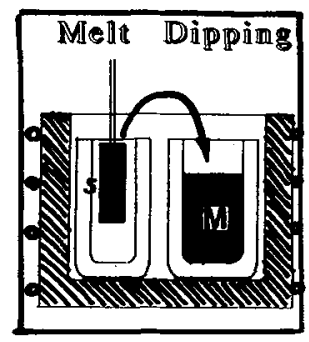

b

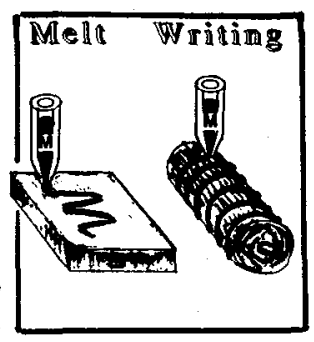

c

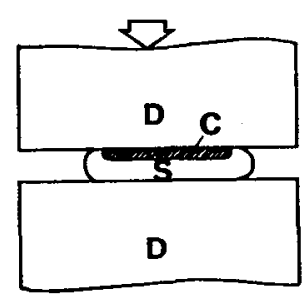

d

Fig. 1. - A schematic drawing for: a) melt-spinning; b) melt-dipping; c) melt-writing; d) press-coating techniques. $\mathrm{C}$ is the coating, $\mathrm{D}$ is the dies and $\mathrm{S}$ is the substrate.

\section{Oxidation of metallic precursors.}

The metallic precursors were converted into superconducting oxides by first oxidation, and then annealing. During the oxidation stage, all the metallic elements were fully oxidized, except for silver, which does not oxidize at elevated temperatures. Due to the existence of 
the reactive elements such as $\mathrm{Ca}$ and $\mathrm{Sr}$ in this alloy system, three different types of oxidation have been observed in different conditions: combustion oxidation, fast oxidation and slow oxidation. Thermogravimetric measurements showed that the combustion oxidation had $\sim 10 \%$ less total mass gain than the slow oxidation, indicating that some components in the alloys were volatilized. Combustion and fast oxidation produced heavily distorted specimens with rough surfaces and Ag segregation, and did not lead to good superconducting properties. The slow oxidation produced non-distorted ribbons with a relatively homogeneous microstructure which can be then processed to the superconducting state with good reproducibility [10]. The oxidation types mainly depended on the oxidation temperature, atmosphere $\left(p_{\mathrm{O}_{2}}\right)$ and the $\mathrm{Ag}$ content in the precursor alloys. The tendencies toward combustion and fast oxidation increased as $p_{\mathrm{O}_{2}}$ and the temperature increased. For example, the temperature of the combustion oxidation for alloy $\mathrm{Bi}_{1.4} \mathrm{~Pb}_{0.6} \mathrm{Sr}_{2} \mathrm{Ca}_{3} \mathrm{Cu}_{4} \mathrm{Ag}_{11}$ was about $630{ }^{\circ} \mathrm{C}$ in $100 \% \mathrm{O}_{2}$ and $680^{\circ}$ in air. On the other hand, Ag played the role of diluent agent slowing down the reaction rate. The combustion temperatures in $100 \% \mathrm{O}_{2}$ for alloys $\mathrm{Bi}_{1.4} \mathrm{~Pb}_{0.6} \mathrm{Sr}_{2} \mathrm{Ca}_{3} \mathrm{Cu}_{4}$ with 24, 25, 55 and $70 \mathrm{wt}$. \% Ag were found to be $\sim 500, \sim 600, \sim 630$ and $\sim 660^{\circ} \mathrm{C}$, respectively. Figure 2 presents three specimens of $\mathrm{Bi}_{1.4} \mathrm{~Pb}_{0.6} \mathrm{Sr}_{2} \mathrm{Ca}_{3} \mathrm{Cu}_{4} \mathrm{Ag}_{11}$ after combustive, fast and slow oxidation, and their cross section micrographs, showing that the slow oxidation produced a more homogeneous microstructure than the other two [10].

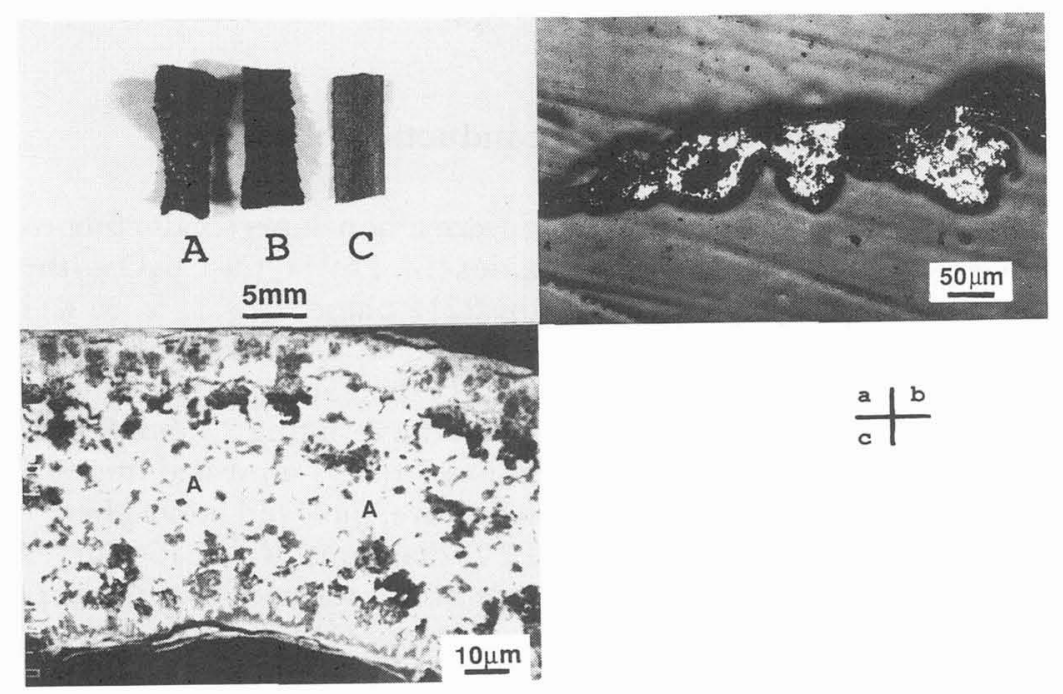

Fig. 2. - a) $\mathrm{Bi}_{1.4} \mathrm{~Pb}_{0.6} \mathrm{Sr}_{2} \mathrm{Ca}_{3} \mathrm{Cu}_{4} \mathrm{Ag}_{11}$ specimens after three types of oxidation: (A) combustion oxidation, (B) fast oxidation and (C) slow oxidation; b) and c) cross section micrographs after combustion and slow oxidation.

Oxidation kinetic studies in the alloys $\mathrm{Bi}_{1.4} \mathrm{~Pb}_{0.6} \mathrm{Sr}_{2} \mathrm{Ca}_{3} \mathrm{Cu}_{4} \mathrm{Ag}_{11-36}$ showed that both cation diffusion and oxygen ion diffusion took place during the slow oxidation processes. Outward diffusion of cations formed oxides near the surfaces (external oxidation) while inward diffusion of oxygen ions caused internal oxidation. Predominant external oxidation formed a Caand $\mathrm{Sr}$ - rich oxide layer near both surfaces and led to a less homogeneous microstructure, while strong internal oxidation resulted in a more chemically homogeneous microstructure 
with small oxide grains distributed in a Ag matrix. The tendency toward either external or internal oxidation depended upon $p_{\mathrm{O}_{2}}$, oxidation temperature and the $\mathrm{Ag}$ content in the alloy. Increasing $p_{\mathrm{O}_{2}}$, decreasing the oxidation temperature and increasing the Ag concentration in the alloy enhance the tendency toward internal oxidation. Figure 3 shows the microstructures of two specimens with strong external and internal oxidation tendencies.

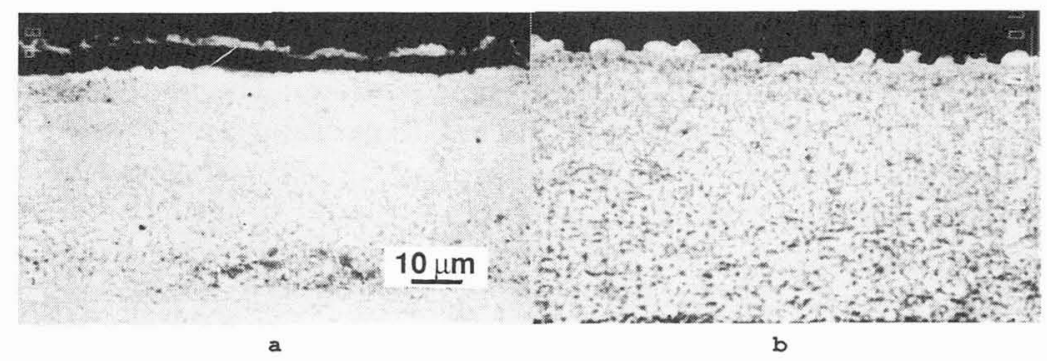

Fig. 3. - Cross section (SEM) micrographs of oxidized $\mathrm{Bi}_{1.4} \mathrm{~Pb}_{0.6} \mathrm{Sr}_{2} \mathrm{Ca}_{3} \mathrm{Cu}_{4} \mathrm{Ag}_{36}$ with strong: a) external; b) internal oxidation tendencies.

\section{Annealing and formation of the superconducting phases.}

The oxides formed during the oxidation stage were a non-superconducting oxide mixture. They were converted into superconducting oxides $(\mathrm{Bi}, \mathrm{Pb})_{2} \mathrm{Sr}_{2} \mathrm{Ca}_{2} \mathrm{Cu}_{3} \mathrm{O}_{X}$ (the 2223 phase, $\left.T_{\mathrm{c}(R=0)} \simeq 110 \mathrm{~K}\right)$ and $(\mathrm{Bi}, \mathrm{Pb})_{2} \mathrm{Sr}_{2} \mathrm{Ca}_{1} \mathrm{Cu}_{2} \mathrm{O}_{\mathrm{Y}}$ (the 2212 phase, $\left.T_{\mathrm{c}(R=0)} \simeq 85 \mathrm{~K}\right)$ by annealing. To study the phase transformations, we applied a traditional metallurgical method by establishing a temperature-time-transformation $(T T T)$ diagram to express the transformation kinetics, with the phase formation defined through the resulting $T_{\mathrm{c}}$ and $J_{\mathrm{c}}[11,12]$. Figure 4 shows the $T T T_{\mathrm{c}}$ diagrams for alloy $\mathrm{Bi}_{1.4} \mathrm{~Pb}_{0.6} \mathrm{Sr}_{2} \mathrm{Ca}_{3} \mathrm{Cu}_{4} \mathrm{Ag}_{11}$ annealed in $5 \% \mathrm{O}_{2}+95 \% \mathrm{Ar}$ and air, exhibiting the effects of annealing temperature, time and atmosphere on the formation of the superconducting phases. In these $T T T_{\mathrm{c}}$ diagrams, "C"-shape curves bound areas of different phases and represent the conditions of the formation of the superconducting phases during isothermal annealing. The areas I, II and III represent three types of superconducting transitions. Type (I) has a superconducting onset and zero resistance temperature from 60 to $85 \mathrm{~K}$, corresponding to a predominate 2212 superconducting phase. Type (II) has superconducting onset transitions above $100 \mathrm{~K}$ and zero resistance temperatures from 60 to $85 \mathrm{~K}$, indicating that the high $T_{\mathrm{c}} 2223$ phase existed, and was not fully self-connected but mixed with the 2212 phase. Type (III) has both the superconducting onset and zero resistance temperatures above $100 \mathrm{~K}$, indicating that the 2223 phase was well developed and self-connected.

In the same way, temperature-time-critical current density diagrams $\left(T T J_{\mathrm{c}}\right)$ were used to describe the relationship of the critical current density and the annealing conditions. Figure 5 shows two $T T J_{\mathrm{c}}$ diagrams for alloys $\mathrm{Bi}_{1.4} \mathrm{~Pb}_{0.6} \mathrm{Sr}_{2} \mathrm{Ca}_{3} \mathrm{Cu}_{4} \mathrm{Ag}_{11}$ and $\mathrm{Bi}_{1.4} \mathrm{~Pb}_{0.6} \mathrm{Sr}_{2} \mathrm{Ca}_{3} \mathrm{Cu}_{4} \mathrm{Ag}_{21}$ respectively, exhibiting the effect of $\mathrm{Ag}$ content on the superconductivity. The three areas (I, II and III) in figure 5 represent the annealing conditions which produced superconductors with $J_{c(T=77)}=5-100,100-300$ and $>300 \mathrm{~A} / \mathrm{cm}^{2}$, respectively. From the kinetic results shown 


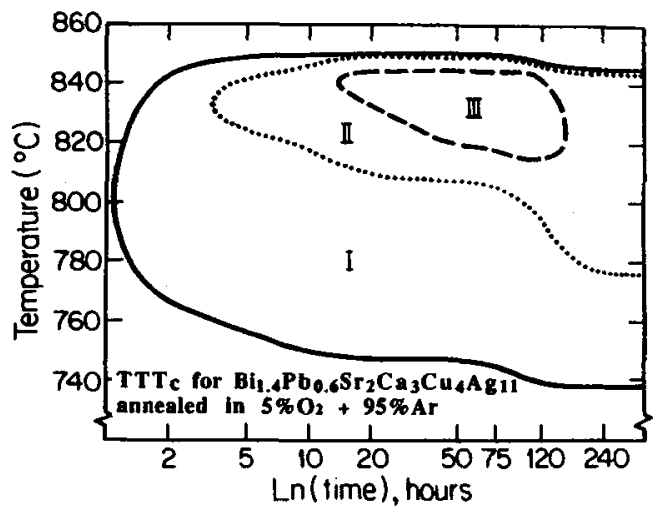

a

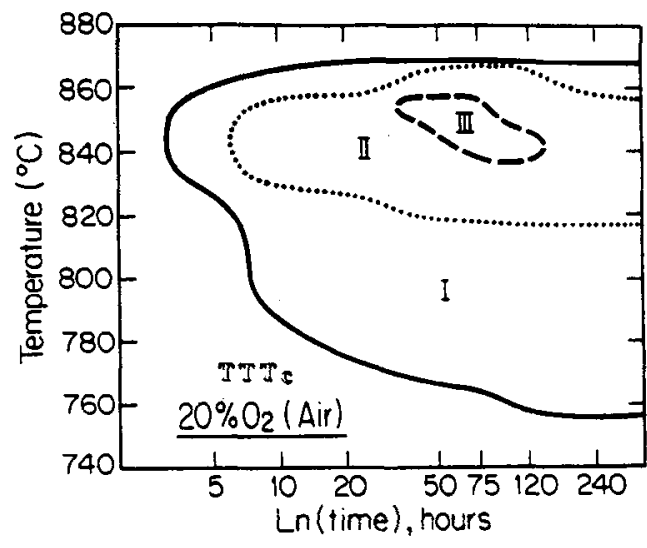

b

Fig. 4. - Temperature-Time- $T_{\mathrm{c}}$ diagram for $\mathrm{Bi}_{1.4} \mathrm{~Pb}_{0.6} \mathrm{Sr}_{2} \mathrm{Ca}_{3} \mathrm{Cu}_{4} \mathrm{Ag}_{11}$ annealed in: a) $5 \% \mathrm{O}_{2}+95$ $\% \mathrm{Ar} ; \mathrm{b})$ air $\left(21 \% \mathrm{O}_{2}\right)$.

in figure 4, we can see that "C"-shape curves bound areas of different phases in the $T T T_{\mathrm{c}}$ diagrams, evidence of a diffusion controlled phase transformation. The low $T_{c} 2212$ phase formed over a wide range of annealing temperature and time, while the high $T_{\mathrm{c}} 2223$ phase formed in a much smaller area inside the 2212 formation area, indicating that the 2223 phase was formed from the 2212 phase. The area III in figure 4 showed a closed loop instead of a "C" shape open curve, indicating that the high $T_{c} 2223$ phase was not stable. It decomposed into non-superconducting phases after long times at that temperature with a deterioration of the superconducting properties.

The formation of the superconducting phases was found to be affected by the oxygen partial pressure. Increasing $p_{\mathrm{O}_{2}}$ from 5 to $21 \%$ shifted the "C" curves to a position of higher temperature and longer time, and reduced the size of area III (see Fig. 4), while decreasing $p_{\mathrm{O}_{2}}$ from 5 to $0.01 \%$ moved the "C" curves to a lower temperature position and also reduced the size of the "C" curves.

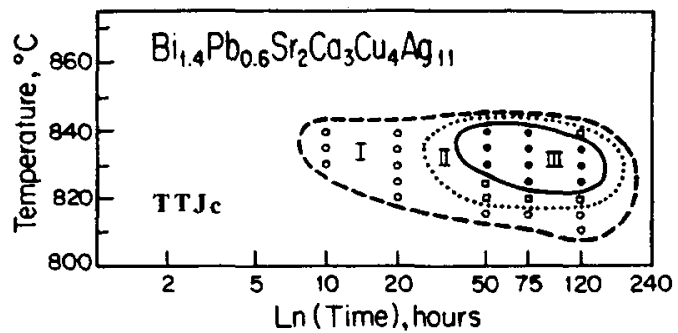

Area I $J_{c}=5.100 \mathrm{~A} / \mathrm{cm}^{2}$, Area II $-J_{c}=100.300 \mathrm{~A} / \mathrm{cm}^{2}$, Area III $\cdot J_{c}=>300 \mathrm{~A} / \mathrm{cm}^{2}$ Critical currents were defined as $1 \mu v / \mathrm{cm}$,

Jc were calculated by using the full specimen cross-section.

a

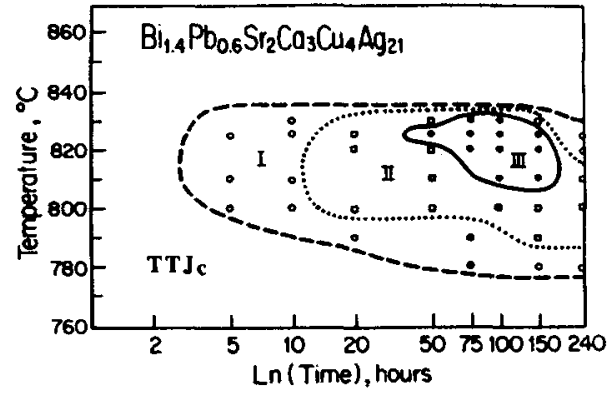

b

Fig. 5. - Temperature-Time- $J_{\mathrm{c}}$ diagrams for: a) $\mathrm{Bi}_{1.4} \mathrm{~Pb}_{0.6} \mathrm{Sr}_{2} \mathrm{Ca}_{3} \mathrm{Cu}_{4} \mathrm{Ag}_{11}$; b) $\mathrm{Bi}_{1.4} \mathrm{~Pb}_{0.6} \mathrm{Sr}_{2} \mathrm{Ca}_{3} \mathrm{Cu}_{4}$ $\mathrm{Ag}_{11}$. 


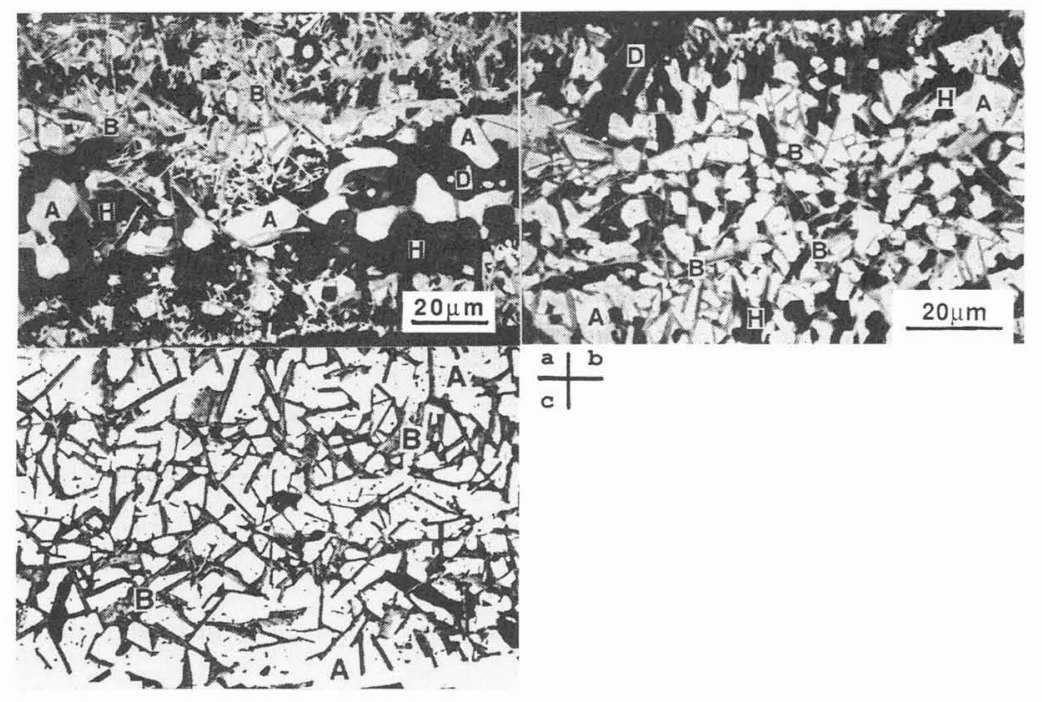

Fig. 6. - Cross section SEM (BSE) micrographs from specimens a) $\mathrm{Bi}_{1.4} \mathrm{~Pb}_{0.6} \mathrm{Sr}_{2} \mathrm{Ca}_{3} \mathrm{Cu}_{4} \mathrm{Ag}_{3}$; b) $\left.\mathrm{Bi}_{1.4} \mathrm{~Pb}_{0.6} \mathrm{Sr}_{2} \mathrm{Ca}_{3} \mathrm{Cu}_{4} \mathrm{Ag}_{11} ; \mathrm{c}\right) \mathrm{Bi}_{1.4} \mathrm{~Pb}_{0.6} \mathrm{Sr}_{2} \mathrm{Ca}_{3} \mathrm{Cu}_{4} \mathrm{Ag}_{21}$, after controlled oxidation and annealing. The bright areas are $\mathrm{Ag}$ (marked $\mathrm{A}$ ), the plate-like gray grains are the 2223 phase (marked B), the dark grey areas are calcium and copper rich oxides (marked D), and the areas marked $\mathrm{H}$ are pores.

$J_{\mathrm{c}}$ is a much more processing sensitive property than $T_{\mathrm{c}}$. While the $T_{\mathrm{c}}$ were all high in the three areas in figure $5\left(T_{\text {onset }}=112-118 \mathrm{~K}, T_{R=0}=104-110 \mathrm{~K}\right)$, the $J_{\mathrm{c}(T=77 \mathrm{~K})}$ varied by two orders of magnitude. This suggests that while a connected path for the 2223 phase can be made by annealing over a wide range of temperature and time combination, the volume fraction and connectivity of the 2223 phase (and thus $J_{\mathrm{c}}$ ) is a much more sensitive function of these processing conditions.

Silver additions were clearly beneficial for formation of the high $T_{\mathrm{c}} 2223$ phase by shortening the phase formation time, lowering the annealing temperature, and improving the stability of the 2223 phase (Fig. 5). Specimens with higher $\mathrm{Ag}(70-80 \mathrm{wt} . \%)$ also have a higher $J_{\mathrm{c}}$ and a better $J_{\mathrm{c}}$ reproducibility because the microstructure is more homogeneous. Figure 6 is a set of SEM backscattered electron (BSE) micrographs, showing the longitudinal cross section microstructure from $\mathrm{Bi}_{1.4} \mathrm{~Pb}_{0.6} \mathrm{Sr}_{2} \mathrm{Ca}_{3} \mathrm{Cu}_{4} \mathrm{Ag}_{3}, \mathrm{Bi}_{1.4} \mathrm{~Pb}_{0.6} \mathrm{Sr}_{2} \mathrm{Ca}_{3} \mathrm{Cu}_{4} \mathrm{Ag}_{11}$ and $\mathrm{Bi}_{1.4} \mathrm{~Pb}_{0.6} \mathrm{Sr}_{2} \mathrm{Ca}_{3} \mathrm{Cu}_{4} \mathrm{Ag}_{21}$ after suitable oxidation and annealing. BSE images exhibit different contrast from the different phases consisting of different elements, i.e. elements with higher atomic number showed brighter contrast. Silver grains (marked A) showed bright contrast and the oxide grains exhibited grey or black contrast. The 2223 superconducting oxide (marked B) was shown to be plate-like grains. Microanalysis from 10 points in this phase gave an average composition (at. \%) of $20.1 \mathrm{Bi}, 2.1 \mathrm{~Pb}, 21.5 \mathrm{Sr}, 20.7 \mathrm{Ca}$ and $31.3 \mathrm{Cu}$, very near the stoichiometric ratio of $2: 2: 2: 3$. There were a small number of dark grains, which were found to be several types of $\mathrm{Ca}$ and $\mathrm{Cu}$ rich oxides and $\mathrm{CaPbO}_{3}$ by microanalysis and $\mathrm{X}$ ray diffraction $[11,12]$. Although the three alloys here all showed microstructures with well developed plate-like 2223 phase, their microstructures are different. While the specimens with less Ag showed a less homogeneous microstructure with large Ag segregation and pores, the microstructure of the high- $\mathrm{Ag}$ specimens is more homogeneous, with the 2223 grains 
embedded in a Ag matrix. Thus Ag apparently improves the connection between the 2223 grains and therefore increases $J_{c}$.

\section{Mechanical deformation.}

Efforts have been made to produce textured superconducting oxides with improved $J_{c}$. Mechanical deformation such as pressing, rolling and drawing was used in the Bi-superconductor system with success $[13,14]$. When we used press coating to produce a BSCCO/Ag superconducting layer on a metallic substrate [9], we noticed that the mechanical pressing produced BSCCO/Ag coatings with a textured microstructure and an improved $J_{c}$. Cyclic deformation and annealing lead to even better results $[16,17]$.

Multilayered ribbons ( 10 layers) were tightly wrapped with thin $\mathrm{Ag}$ sheets, placed horizontally between two dies and subjected to a vertical pressure of 5-20 MPa at $20-400{ }^{\circ} \mathrm{C}$. A thickness reduction ratio $R=\left(t_{1}-t_{2}\right) / t_{1}$ was used to describe the deformation extent where $t_{1}$ and $t_{2}$ are the thickness of the BSCCO/Ag cores before and after deformation. Mechanical deformation forced the 2223 grains to become aligned with the "c" direction perpendicular to the ribbon basal plane. Figure 7 shows two X-ray diffraction spectra from a specimen after cyclic deformation and annealing (textured) and the same specimen ground into powder (non-textured). The (001) lines from the 2223 phase, especially (002), (0010), (0012) and (0014) appear to be the strongest in the textured sample, while (015), (017), (019) and (110) are the strongest in the powder sample. The Lotgering factor, $F$ [15], was calculated based on the ratio of the intensities for $(001)$ and all (hkl) reflections [15, 17], and used to quantify the degree of texture. The $F$ factor varies from 0 (non-oriented) to 1 (completely oriented), and was found to be $\sim 0.85$ for the specimen shown in figure 7a. The degree of texture is a function of the deformation. Figure 8 shows a plot of the $F$ factor versus deformation extent, $R$. The four points in the plot with increasing $R$ correspond to the specimens after $1,2,3$ and 4 cycles of deformation and annealing. The deformation extents were $\sim 50,80,90$ and $97 \%$, with a measured $F$ of $0.24,0.51,0.69$ and 0.89 , respectively. Figure 9 shows a plot of $J_{c}$ versus $F$, indicating that the specimen's $J_{c}$ increased with the degree of the texture in the 2223 phase. Figure 10 shows a group of SEM micrographs (BSE) for four specimens after identical treatments to the specimens in figures 8 and 9 . The gray, elongated phase is the 2223 superconducting phase and the bright areas are $\mathrm{Ag}$. The apparent texture in the specimens is enhanced by the number of cycles in the deformation-annealing sequence, consistent with the measured $F$ factors.

Because the superconducting oxides are brittle, mechanical deformation created microcracks and damaged the connection between the oxide grains. Therefore, $J_{\mathrm{c}}$ is usually low after deformation. A re-annealing at $800^{\circ} \mathrm{C}$ is needed to recover the 2223 grains through grain growth. However, excess re-annealing (at higher temperature or for longer times) caused degradation of the textured structure and a decrease in $J_{\mathrm{c}}$.

The $J_{\mathrm{c}}$-magnetic field dependence is a very important property for bulk superconductors. The deformation-texturing process reduced the $J_{c}$-magnetic field sensitivity. Figure 11 shows the $J_{c}$ behavior in a magnetic field perpendicular to the ribbon surface. In a field of $20 \mathrm{mT}$, the $J_{c}$ of a simple annealed ribbon dropped to about $2 \%$ of the value in zero field, while the $J_{\mathrm{c}}$ of the well textured specimens are retained at $\sim 50 \%$. This behavior is also a function of the mechanical deformation extent and the texture factor [18]. These results indicate that the deformation-annealing treatment improved the grain boundary properties of the superconducting oxide and the weak-link behavior $[18,19]$. 


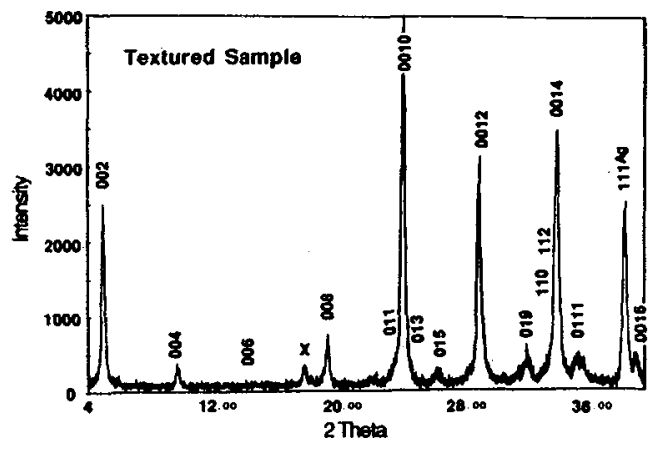

a

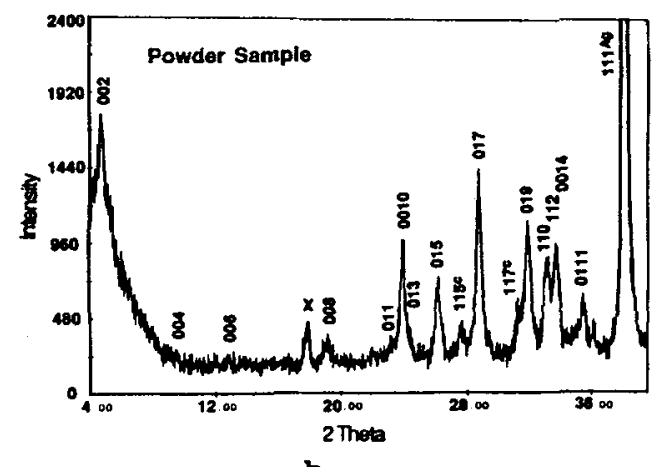

b

Fig. 7. - X-ray diffraction spectra from: a) textured; b) non-textured samples. Notice the (001) diffraction maxima are very strong in the textured sample.

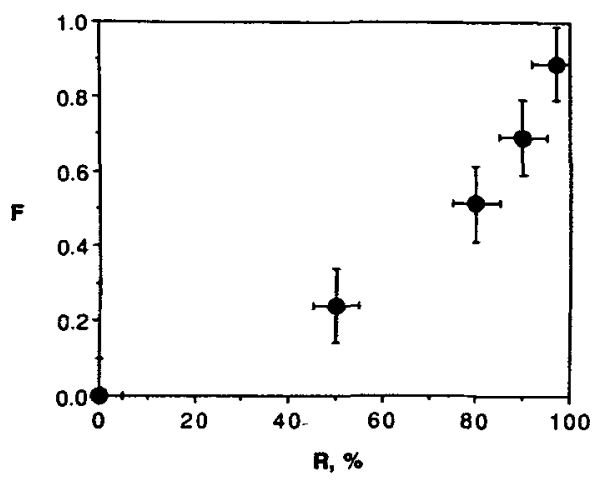

Fig. 8 .

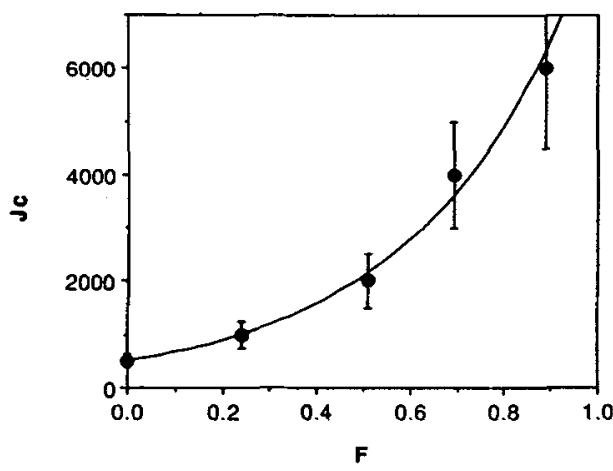

Fig. 9.

Fig. 8. - A plot of texture factor $F$ versus deformation extent $R$ for specimens after 1, 2, 3 and 4 cycles of deformation and annealing.

Fig. 9. - A plot of $J_{c}$ versus texture factor $F$ for the specimens after 1,2,3 and 4 cycles of deformation and annealing.

\section{Conclusions.}

A high temperature oxidation method has been developed to produce high $T_{\mathrm{c}}$ superconductors. $\mathrm{Bi}-\mathrm{Pb}-\mathrm{Sr}-\mathrm{Ca}-\mathrm{Cu}-\mathrm{O} / \mathrm{Ag}$ superconducting ribbons with $T_{\mathrm{c}(R=0)}$ at 104 to $110 \mathrm{~K}$ and an engineering $J_{\mathrm{c}}$ as high as $10000 \mathrm{~A} / \mathrm{cm}^{2}$ at $77 \mathrm{~K}$ were produced in this way.

Three types of oxidation, combustion, fast and slow oxidation, were observed under different conditions. While the combustion and fast oxidation produced distorted, chemically segregated microstructures, slow oxidation produced non-deformed specimens with a relatively homogeneous mixture of oxide and Ag, from which the 2223 superconducting phase can be formed after suitable annealing.

The formation of the superconducting phases were diffusion controlled solid-state reactions. The 2223 phase formed over a much smaller temperature and time range compared 


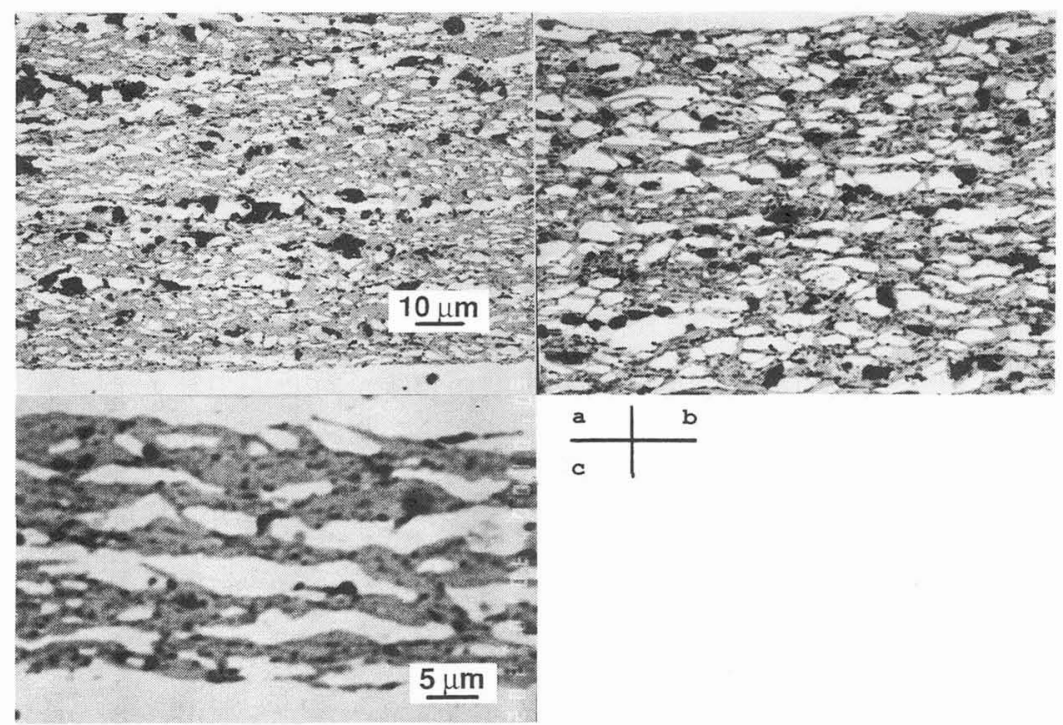

Fig. 10. - Cross section SEM (BSE) micrographs from specimens after: a) 2; b) 3; c) 4 cycles of deformation and annealing. Notice the apparent texture in the microstructure is enhanced by the repetition of the deformation-annealing cycle.

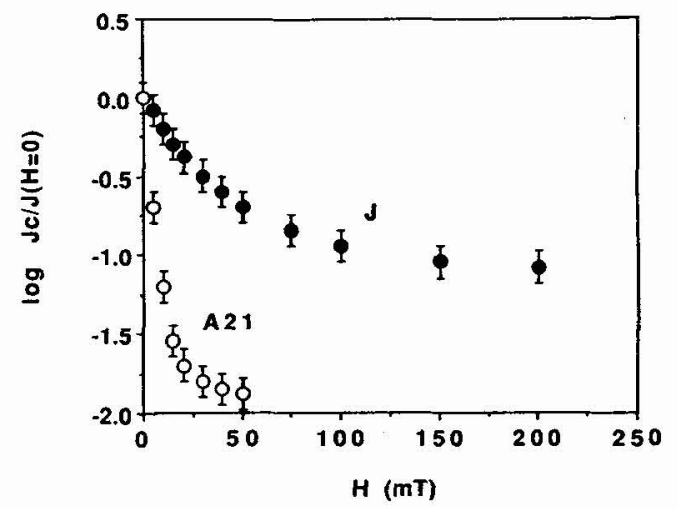

Fig. 11. - Two plots of $J_{\mathrm{c}}$ versus magnetic field $H$ for textured $(\mathrm{J})$ and non-textured (A21) specimens.

with the 2212 phase, suggesting that the 2223 phase grew from the 2212 phase via diffusion. Adding Ag to the alloy resulted in a number of beneficial effects related to the ease processing and specimen homogeneity. Ag decreases the oxidation rate, reduces the specimen porosity, and promotes the formation and improves the inter-connection of the 2223 phase. A combination of mechanical deformation and annealing produced specimens with a textured microstructure and greatly improved $J_{\mathrm{c}}$, and also improved the $J_{\mathrm{c}}$ in a magnetic field. The present method has the advantages of mass production, ease of control of the process, and flexibility in shaping the products. 


\section{Acknowledgements.}

This project is supported by DOE contract No DE-FGO2-85ER 45179.

\section{References}

[1] NeWkirk M.S., UrquhaRT A.W., Zwicker H.R., Breval E., J. Mater. Res 1 (1986) 81.

[2] NAGELBERG A.S., J. Mater. Res. 7 (1992) 265.

[3] YUREK G.J., VANDER SANDE J.B., WANG W.X., RudMan D.A., ZHANG Y., MATTHiesen M.M., Metall. Trans. 18A (1987) 1813.

[4] GaO W., RudMan D.A., VANDER SANDE J.B., JOM (June, 1990) p. 19.

[5] Chen H.S., Liou S.H., Kortan A.R., Kimerling L.C., Appl. Phys. Lett. 53 (1988) 705.

[6] Gao W., Li S.C., Parrella R., Rudman D.A., Vander Sande J.B., J. Mater. Sci. 26 (1991) 4186.

[7] GaO W., VANDer SANDE J.B., Physica $C 171$ (1990) 69.

[8] GaO W., VANDER SANDE J.B., Mater. Sci. Eng. B8 (1991) 63.

[9] GAO W., VANDER SANDE J.B., Mater. Lett. 10 (1991) 444.

[10] GaO W., Li S.C., Rudman D.A., Yurek G.J., VAnder SAnde J.B., J. Electrochem. Soc. 137 (1990) 1951.

[11] Gao W., Li S.C., Parrella R., Rudman D.A., Vander Sande J.B., J. Mater. Res. 5 (1990) 2633.

[12] Gao W., Li S.C., Rudman D.A., VANder SANde J.B., Physica $C 167$ (1990) 395.

[13] Heine K., Tenbrink J., Thoner M., Appl. Phys. Lett. 55 (1989) 2441.

[14] Sato K., Hikata T., Mukai H., Ueyama M., Shibuta N., Kato T., Masuda T., Nagata M., IWATA K., Mitsui T., IEEE Trans. Magn. 27 (2) (1991) 1231.

[15] Lotgering F.K., J. Inorg. Nucl. Chem. 9 (1959) 113.

[16] Gao W., VANDER SANDE J.B., Physica $C 181$ (1991) 105.

[17] GaO W., VANDER SANDE J.B., Supercond. Sci. Tech. 5 (1992) 318.

[18] Gao W., Vander Sande J.B., Physica $C 192$ (1992) 173.

[19] Dimos D., Chaudhari P., Mannhart J., Le Goues F.K., Phys. Rev. B 41 (1990) 4038. 